\title{
DIMENSÕES E COMPLEXIDADE DA GERÊNCIA DA TECNOLOGIA
}

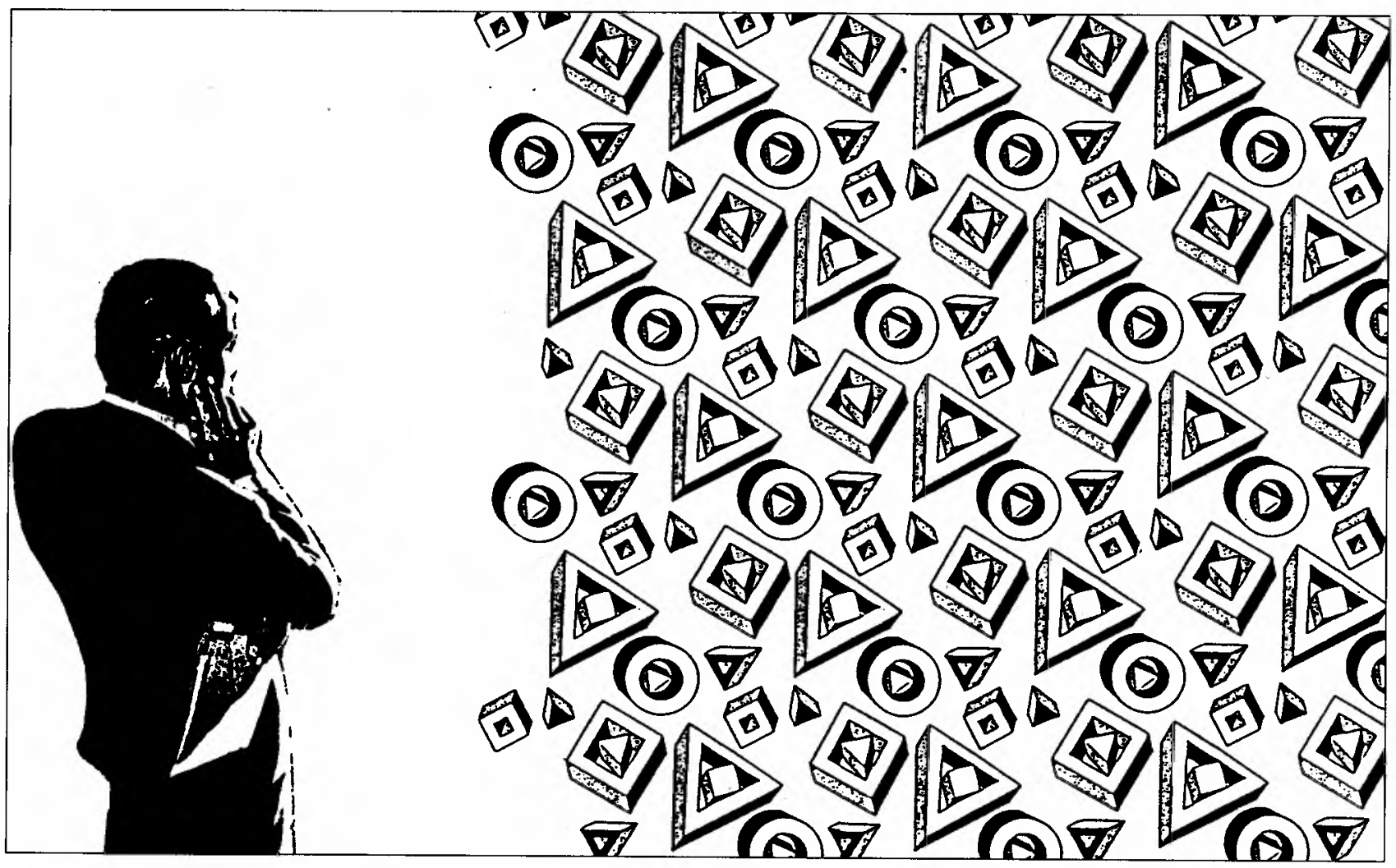

Indiana Pinheiro da Fonseca Rodrigues

Professora Adjunta do Departamento de Ciências

Administrativas e Coordenadora do Curso de

Mestrado em Administração da UFMG.

Abigail de Oliveira Carvalho

Professora Adjunta e Chefe do Departamento de Ciências Administrativas da UFMG.

* RESUMO: Como a sociedade moderna é uma sociedade de organizações e a tecnologia um fator crítico na consecução das atividades produtivas, a função da gerência da tecnologia ocupa uma posição central no contexto organizacional. Enquanto fator de produção e bem negociável, a tecnologia tem as características de ser um recurso escasso e intangivel; sua produção é complexa; de tempo imprevisível; custo indeterminado; e uso econômico incerto. As dimensões da gerência da tecnologia podem ser definidas de acordo com o conteúdo do conhecimento mais relevante para o exercicio de cada atividade e são, no mínimo, três: a dimensão especializada, a dimensão humana e a dimensão lógico-analítica.
* PALAVRAS-CHAVE: Tecnologia, características da tecnologia, gerência, função gerencial, dimensões da gerência da tecnologia.

* ABSTRACT: Organizations are ubiquitous entities in modern societies. Technology is a critical factor to every activity in any organization, so technological management is central to organizational processes. Technology is a factor for production; a marketable product; and an insubstantial and scarce resource. The process to develop new technologies is a complex one, the costs of which are usually difficult to determine as well as the time to get the expected results. The achievement of the desired product or process is no guarantee of its economic utility. The dimensions of technological management can be defined according to the content of knowledge relevant to the functional activities and should be three at minimum: a specialized dimension; a human dimension; and a logical-analytical dimension.

* KEY WORDS: Technology, technological features, management, managerial function, dimensions of technological management. 


\section{INTRODUĢÃO}

$\mathrm{E}$ ntendida como "conjunto organizado de conhecimentos - científico, empírico, intuitivo - empregados na produção e comercialização de bens e serviços", a tecnologia ocupa uma posição central na execução de qualquer atividade humana. Desde que o homem confeccionou as primeiras ferramentas e armas, que the possibilitaram controlar a natureza para sua sobrevivência e proteção, até os dias atuais, o desenvolvimento da tecnologia e das sociedades modernas são duas faces de uma mesma moeda. De base intuitiva, o progresso técnico avançou para crescente incorporação de base empírica e científica, chegando, neste final de século, às tecnologias novas de alto conteúdo científico.

$\mathrm{Na}$ formação e transformação das sociedades, através da interação contínua dos agentes sociais, a evolução tecnológica a parece como fonte e resultado da reconstrução social ${ }^{1}$. O corolário dessa evolução é o aumento em complexidade da sociedade moderna - que é hoje uma sociedade de organizações - e da gerência da tecnologia, que é um fator crítico na consecução das atividades produtivas.

A teoria das organizações ocupa-se das funções gerenciais, no que dizem respeito à gestão financeira, mercadológica, de produção e de pessoal, mas tem negligenciado a gerência da tecnologia ${ }^{2}$. No entanto, a função da gerência da tecnologia ocupa uma posição central no contexto organizacional. A própria manutenção da organização repousa na sua capacidade de fazer escolhas de tecnologias adequadas às atividades que desenvolve, i.e., de tecnologias que assegurem a produção de bens e serviços de qualidade igual ou melhor do que aquela dos bens e serviços produzidos por seus concorrentes. Neste sentido, a tecnologia necessária a cada organização apresenta-se também como um fator difícil de ser substituído.

Um recurso organizacional que é crítico, central e de difícil substituição é elemento de incerteza para a organização, constituindo-se por isso, em fonte de poder para aqueles que detêm o controle desse recurso ${ }^{3}$, e leva a função de gerência da tecnologia a assumir um caráter estratégico.

Ao mesmo tempo, o domínio do conhecimento tecnológico é, para a organização, fonte de poder frente a seus concorrentes e o comércio da tecnologia é por natureza desigual. Nesse comércio o vendedor terá sempre mais poder de barganha quanto menos o comprador tiver domínio do conhecimento implícito na tecnologia negociada e quanto menor for sua capacidade para desenvolver a tecnologia de que precisa.

A tendência de aumento na velocidade da mudança tecnológica é um desafio para as organizações. Impõe a necessidade crescente de atualização, se não para assegurar uma posição de vanguarda, pelo menos para acompanhar de perto as transformações. Parece não haver dúvida de que o não atendimento dessa demanda tende a aumentar a distância entre as organizações na corrida concorrencial, significando a médio e longo prazo a morte daquelas retardatárias.

No plano macroeconômico da competição internacional, o domínio tecnológico aparece como fonte de poder e autonomia das nações, aumentando a complexidade das transações que envolvem transferência de tecnologia. Nesse quadro, a questão da gerência da tecnologia não pode deixar de ser preocupação central para as organizações. Se até hoje ela não mereceu um lugar de destaque na teoria das organizações, isso não quer dizer que os estudiosos ignorem a variável tecnologia. No entanto, eles a têm tratado como uma variável exógena independente ${ }^{4}$, portanto não suscetível a gerenciamento dos atores organizacionais.

Nossa proposta é refletir sobre as propriedades da tecnologia enquanto recurso crítico e estratégico para as organizações numa tentativa de identificar as dimensões relevantes da gerência da tecnologia, de modo a contribuir para formulação de uma teoria da gestão da tecnologia. Nosso objetivo é, antes de tudo, incentivar o debate a partir de especulações que tentam entender a relação entre a natureza e o trato das questões de gerência da tecnologia nas organizações.

\section{CARACTERÍSTICAS DA TECHOLOGIA}

Ao mesmo tempo que é um fator de produção indispensável para a organização, a tecnologia é também um bem comercializável. Como o mercado de qualquer outro bem, o mercado da tecnologia tem características que lhe são próprias e estão associadas à natureza do objeto de negociação. A comercialização se dá com a transferência de um produto do vendedor para o comprador. Apresentando-se sob a forma de conhecimento materializado, a 
tecnologia tem a característica de ser um bem intangivel. Nesse caso, a transferência processada no ato de comercialização é a transferência de conhecimento, que pode estar registrado em documentos escritos ou na cabeça das pessoas. A compra de tecnologia exige, portanto, do comprador, que ele seja capaz de absorver um conhecimento especializado e a transação fica limitada a grupos de especialistas e a uma linguagem dificilmente inteligível para o leigo. Ainda por se tratar de transferência de conhecimento, o comércio de tecnologia não se esgota no ato da compra, mas ocorre por etapas, envolvendo absorção, adaptação, aperfeiçoamento, inovação e difusão ${ }^{5}$.

Por se tratar de um recurso estratégico, a oferta de tecnologia é escassa e problemática; e requer, de quem a procura, informações tanto das fontes onde pode estar disponível quanto da adequabilidade de seu uso para os fins desejados. Quem detém uma tecnologia tem a propriedade de um recurso estratégico, não o coloca à venda, mas antes, tenta protegê-lo e só irá cedê-lo em condições que mantenham sua vantagem comparativa. O sistema de patentes é a forma legal de proteção da propriedade de tecnologia funcionando como seguro de um bem raro e valioso. A tecnologia desenvolvida por uma empresa tem geralmente um custo muito alto, é o trunfo que lhe garante uma posição vantajosa no mercado, por isso o segredo industrial é uma prática vigente nos setores mais avançados.

O desenvolvimento de tecnologia é uma atividade complexa. Exige perspicácia, criatividade, além de ser um processo cumulativo, na medida em que se fundamenta em conhecimento científico e tecnológico desenvolvido anteriormente ${ }^{6}$.

A pesquisa tecnológica tem ainda o caráter de uma atividade de alto risco. Não é possível precisar o tempo de produção ou mesmo o volume de recursos que serão comprometidos até se obter algum resultado. Quando se chega a um resultado, seja um novo produto ou novo processo, seu uso econômico ainda é incerto. Embora a produção de uma tecnologia não tenha, na maioria das vezes, sua origem na pesquisa básica, para efeito de compreensão dos riscos incorridos em sua produção, a escala proposta por Veado é ilustrativa ${ }^{7}$. Segundo o autor, passando pelas diversas etapas do processo de produção de tecnologia, da pesquisa básica até a instalação industrial, as incertezas com relação aos resultados tendem a decrescer e os custos tendem a crescer. Definindo risco como o produto da incerteza pelo custo, este pode permanecer constante se a variação oposta dos dois fatores ocorrer no mesmo nível.

As incertezas do mercado, o movimento dos concorrentes e a imprevisibilidade do comportamento econômico dos agentes sociais, são riscos adicionais quanto à viabilidade do uso econômico da tecnologia produzida. Enquanto fator de produção e bem negociável, a tecnologia tem as características de ser um recurso escasso, intangível, de produção complexa (de tempo imprevisível e custos indeterminados) e uso econômico incerto.

\section{A FUNÇÃO GERENCIAL}

Desde Fayol, a gerência dos recursos das organizações é objeto de estudo da teoria da administração, quer em sua vertente analítico-descritiva, quer em sua vertente normativo-prescritiva. A gerência tem sido estudada como uma função genérica essencial para a condução das organizações ou como função parcelada responsável pela ordenação, manutenção e direção das funções básicas em cada organização. Uma vasta literatura é dedicada à gerência de pessoal, da produção, de finanças e de marketing, pois o sucesso da organização depende do gerenciamento eficaz de suas atividades básicas.

Parece existir uma desconfiança sobre a qualidade acadêmica dos estudos relativos à função gerencial. O termo função não é previamente definido e passa a ter uma abrangência que prejudica a precisão necessária à clareza dos conceitos. $O$ fato de haver mais dúvidas que respostas em relação à questão não desmerece, a nosso ver, a discussão do tema.

A natureza da função do administrador ou função gerencial começou a ser tratada de forma sistemática por Fayol. Os estudos subseqüentes foram fortemente marcados por sua classificação: prever, organizar, comandar, coordenar e controlar. Há vários autores que apresentam abordagens semelhantes, como por exemplo, Barnard - que realça a coordenação como elemento fundamental da função do administrador - ou Drucker - para quem, obter recursos e desenvolver pessoas são atividades prioritárias dogerente. Há também algumas classificações alternativas que complementam ou contradizem a abordagem do pioneiro da Administração. Tais classificações são resultados de pesquisas empíricas de autores como Carlson, Mintzberg e Stewart.
5. LONGO, W.P. Tecnologia e soberania nacional. São Paulo, Nobel, 1984.

6. LAND, D.E. "Como dirigir a organização do conhecimento". In: DRUCKER, P.F. For mação de dirigentes. Rio de Janeiro, Expressão e Cultura, 1971, pp. 169-202.

7. VEADO, J.C. "O planejamento e o orcamento da atividade científica e tecnológica numa abordagem sistêmica: um esboço preliminar". Ci. Inf., Brasília, 14(2):73-91, jul./dez. 1985. 
A tese de doutoramento defendida por Mintzberg na Sloan School of Management do MIT em 68, publicada pela primeira vez em livro em 1973, pela Harper \& Row, estuda o conteúdo e as características do trabalho gerencial usando uma metodologia de observação estruturada em que as categorias foram desenvolvidas durante e depois da observação com o objetivo de obter uma descrição mais objetiva e mais útil, segundo o autor, da atividade do gerente.

Após a realização da tese, Mintzberg $^{8}$ continuou suas pesquisas sobre o mesmo tema e formou escola. Analisou agendas de executivos, dossiers, e observou minuciosamente as atividades de chefes, diretores, presidentes. As conclusões a que chegou têm desmitificado algumas idéias anteriormente difundidas. Buscou a compreensão do que é o trabalho do administrador (daquele que tem a responsabilidade pela organização como um todo ou por parte dela), quais suas atividades, como se caracterizam, quais seus papéis básicos. Tentou também encontrar as diferenças entre os diversos tipos de cargos, variações essas que aparecem no exercício de papéis aos quais se dá maior ou menor atenção ou em características do trabalho mais ou menos atenuadas.

As características mais comuns do trabalho do gerente são assim descritas:

1. o gerente trabalha muito, em ritmo intenso;

2. a atividade caracteriza-se pela brevidade, variedade e fragmentação;

3. o gerente desenvolve preferência pela ação, em ambiente do tipo estímulo-resposta, age sob pressão, não é o planejador sistemático e reflexivo que se supunha;

4. utiliza-se principalmente dos contatos informais, da comunicação oral, através de meios como reuniões e telefonemas, para obter as informações de que necessita;

5. mantém uma rede complexa de relações horizontais e com grande variedade de pessoas externas à organização;

6. exerce um certo grau de controle sobre seu próprio trabalho, apesar dos compromissos.

8. MINTZBERG, $H$. The nature of managerial work. New York, Harper \& Row, 1973.

9. STEWART, R. "The nature of management? A problem for management education". Journal of Management Studies, 21(3):323-30, jul. 1984. dade formal de que está investido e que impõe ao gerente obrigações de caráter social e legal; o papel de líder, no qual define o clima organizacional, através do seu relacionamento com os subordinados; o papel de agente de ligação, em que se estabelece a rede de contatos externos.

A segunda categoria, papéis ligados à informação, abrange a obtenção de informações (papel de monitor), a disseminação interna (disseminador) e externa (porta-voz) das informações.

Os papéis do terceiro grupo, ligados à tomada de decisões, incluem o papel de empreendedor, pelo qual o gerente promove mudanças controladas, faz adaptações necessárias, inicia projetos; o de manipulador de distúrbios em que responde às pressões resultantes de situações imprevisíveis; o de alocador de recursos em que projeta a estrutura da sua unidade, $o$ modelo de relacionamento formal, e a distribuição de seu próprio tempo; $\mathrm{e}$ finalmente, $\mathrm{o}$ papel de negociador, que absorve considerável tempo do gerente em atividades como contratos de serviço, de vendas, acordos em geral.

Além dos papéis básicos, há outros considerados desdobramentos e que são desempenhados em situações específicas, como é o caso do papel do especialista, encontrado nos administradores profissionais ou gerentes técnicos. As pesquisas levaram a concluir que as ênfases dadas aos vários papéis são variadas, em função de fatores como área funcional, nível hierárquico, setor público ou privado, ambiente, época, personalidade do ocupante do cargo. Por exemplo, os administradores de vendas dão mais importância aos papéis interpessoais, e os administradores especialistas, aos papéis ligados à informação.

Algumas pesquisas mais recentes de Stewart $^{9}$ chamam a atenção para as diferenças entre as atividades gerenciais, em trabalhos similares, e põem em dúvida a extensão do núcleo comum dessas atividades.

Uma dificuldade na abordagem de Mintzberg é inerente às classificações em geral: as categorias não são sempre mutuamente exclusivas; há uma certa superposição que faz com que algumas atividades desempenhadas possam corresponder a mais de um papel, como é o caso da atividade de manter contatos interpessoais, que se pode enquadrar também nos papéis ligados à informação.

A grande qualidade dessa abordagem, a nosso ver, é sua abrangência, isto é, a sua possi- 
bilidade de absorver ou destacar tarefas desconsideradas em outras listas de atividades do gerente. As pesquisas dos autores ligados a essa corrente têm dado uma boa contribuição para a melhoria efetiva do desempenho do administrador, ao revelarem compreensão e percepção mais amplas dos papéis exercidos realmente. Seus resultados são também vistos como o reaparecimento da questão da intuição na literatura sobre gerência.

A definição do que se pensa que o gerente deve ser e saber para exercer suas funções, e os aspectos de "o que ensinar" e "como ensinar" estão presentes nas temáticas de Mintzberg, Stewart e seguidores.

A diversidade da formação acadêmica de gerentes bem-sucedidos sugere que o conteúdo do saber especializado não é fator determinante para o sucesso gerencial. Colocando a questão de outra forma pode-se perguntar, então: que prática vivida favorece o desenvolvimento de habilidades necessárias para o sucesso no desempenho da função de gerente? E mais, que tipo de saber ou conhecimento têm os indivíduos que desenvolvem habilidades gerenciais quando expostos a essas práticas? O conceito de habilidades gerenciais foi consagrado por Katz ${ }^{10}$ quando identificou diferentes tipos de habilidades (técnica, humana, conceitual) associadas às funções dos gerentes em diferentes níveis hierárquicos da organização.

No nosso entender, a gerência da tecnologia é uma função especializada, multidimensional, variável de acordo com a natureza da atividade relativa à tecnologia. O que estamos sugerindo é que o conhecimento e a prática subsidiam o processo intuitivo da ação gerencial. Contrapondo intuição e razão, a análise de Motta evidencia que a ênfase do racional, prevalente na literatura administrativa, retardou o reconhecimento do intuitivo na função gerencial, que só recentemente passou a receber maior atenção $0^{11}$.

Ainda que de forma especulativa, uma análise dos papéis gerenciais que perpassam as três categorias sugeridas por Mintzberg permite formular algumas hipóteses sobre o conteúdo básico do conhecimento necessário ao processo cognitivo do gerente.

Conhecimentos de conteúdo humanístico parecem ser a base para o desempenho dos papéis de representante da organização, de líder e de agente de ligação, na primeira categoria de papéis interpessoais, e de manipulador de distúrbios e negociador, na terceira categoria de papéis, ligados à tomada de decisões.

Conhecimentos que favorecem a capacidade lógico-analítica do indivíduo parecem ser a base para o desempenho dos papéis de empreendedor e alocador de recursos, na terceira categoria de papéis, ligados à tomada de decisões.

Conhecimentos de conteúdo especializado parecem ser a base para o desempenho dos papéis de monitor, disseminador e porta-voz, na segunda categoria de papéis ligados à informação.

O conhecimento de conteúdo humanístico e a capacidade lógico-analítica formam a base comum e o conhecimento especializado, a base diferencial da formação dos gerentes. A origem dessa diferenciação pode ser encontrada na divisão do trabalho que se dá no interior das organizações (finanças, mercadologia, pessoal etc.) e na área de atuação da organização.

\section{A GERÊNCIA DA TECNOLOGIA}

Sem pretender uma lista exaustiva, podemos apontar um grupo de atividades relacionadas à gestão da tecnologia nas organizações. Essas atividades abrangem a compra/venda de tecnologia, o monitoramento tecnológico, a produção de tecnologia, a implantação/difusão de novas tecnologias. Elas têm todas como cerne a tecnologia, mas o trato desse objeto varia, de acordo com as especificidades de cada atividade.

Tomando esse espectro de atividades e as propriedades da tecnologia dominantes em cada uma delas, podemos definir dimensões da gerência da tecnologia com base numa hierarquia de papéis - usando a taxonomia de Mintzberg - e respectivo conteúdo do conhecimento, no exercício da função gerencial de cada atividade. $O$ quadro 1 sintetiza as relações hipotéticas entre essas variáveis e é sugerido como paradigma para investigação empírica.

O comprador de tecnologia está à procura de um produto intangível, i.e., conhecimento, ainda que materializado em equipamentos, e escasso, i.e., dificilmente está em oferta no mercado. Essa compra requer, antes de mais nada, o monitoramento das tecnologias disponíveis que melhor respondam às necessidades de sua organização. Parece óbvio que o gerente precisa principalmente de conhecimento especializado, indispensável para o reconhecimento e escolha do produto adequado para os fins desejados. Outro papel que o gerente deve de-
10. KATZ, R.L. "As habilitações de um administrador eficiente". Expansão, fev./mar. 1975.

11. MOTTA, Paulo R. "Razão e Intuição: recuperando 0 ilógico na teoria da decisão gerencial". Revista de Administração Pública, Rio de Janeiro, 22(3):77-94, jul./set. 
Quadro 1: Dimensões da Gerência da Tecnologia

\begin{tabular}{|c|c|c|c|}
\hline $\begin{array}{c}\text { Atividade Relativa } \\
\text { a Tecnologia }\end{array}$ & $\begin{array}{c}\text { Características da } \\
\text { Tecnologla }\end{array}$ & $\begin{array}{l}\text { Conteádo do } \\
\text { Conhecimento }\end{array}$ & Papéis \\
\hline Compra de tecnologia & $\begin{array}{l}\text { Recurso escasso } \\
\text { Produto intangível }\end{array}$ & $\begin{array}{l}\text { - especializado } \\
\text { - humanístico }\end{array}$ & $\begin{array}{l}\text { - monitor } \\
\text { - negociador }\end{array}$ \\
\hline Venda de tecnologia & $\begin{array}{l}\text { Produção complexa } \\
\text { Produto intangivel } \\
\text { Recurso escasso } \\
\end{array}$ & $\begin{array}{l}\text { - humanístico } \\
\text { - especializado }\end{array}$ & $\begin{array}{l}\text { - agente de ligação, } \\
\text { negociadar } \\
\text { - porta-voz }\end{array}$ \\
\hline $\begin{array}{l}\text { Produção de } \\
\text { tecnologia }\end{array}$ & Produçāo complexa & $\begin{array}{l}\text { - lógico-analítico } \\
\text { - humanístico } \\
\text { - especializado }\end{array}$ & $\begin{array}{l}\text { - alocador de recursos, } \\
\text { empreendedor } \\
\text { - líder, agente de ligação, } \\
\text { manipulador de distúrbio } \\
\text { - disseminador, porta-voz }\end{array}$ \\
\hline $\begin{array}{l}\text { Implantação/ } \\
\text { difusão de } \\
\text { novas tecnologias }\end{array}$ & Produto intangivel & $\begin{array}{l}\text { - humanístico } \\
\text { - lógico-analítico } \\
\text { - especializado }\end{array}$ & $\begin{array}{l}\text { - líder, agente de ligação, } \\
\text { manipulador de distúrbio, } \\
\text { negociador } \\
\text { - empreendedor, alocador } \\
\text { de recursos } \\
\text { - disseminador }\end{array}$ \\
\hline $\begin{array}{l}\text { Monitoramento } \\
\text { tecnológico }\end{array}$ & Recurso escasso & $\begin{array}{l}\text { - especializado } \\
\text { - lógico-analítico } \\
\text { - humanístico }\end{array}$ & $\begin{array}{l}\text { - monitor, disseminador, } \\
\text { porta-voz } \\
\text { - empreendedor } \\
\text { - agente de ligação, } \\
\text { negociador }\end{array}$ \\
\hline
\end{tabular}

sempenhar na compra de tecnologia é de negociador, que vai requerer dele conhecimento de conteúdo humanístico.

$\mathrm{Na}$ venda de tecnologia, as características mais marcantes ainda são o fato de tratar-se de produto intangível, escasso, produzido através de um processo de alta complexidade e de difícil previsibilidade de resultados. Na atividade de venda da tecnologia, os papéis de agente de ligação e negociador, que exigem para seu exercício conhecimento de conteúdo humanístico, parecem ser os mais importantes. Em ordem de importância, na venda da tecnologia, aparece o papel de porta-voz, transmissor das informações técnicas que interessam ao cliente e que promovem as vantagens do produto de sua organização.

De tempo imprevisivel, custo indeterminado, uso econômico incerto, a produção de tecnologia é complexa. O produto desejado não pode ser antecipado, o processo de produção não é definido mas inventado por trabalhadores, profissionais autônomos. Enquanto tra- balho criativo, a produção de tecnologia só poderá ocorrer em ambiente de liberdade de ação, em que o papel do gerente é, em primeiro lugar, de alocador de recursos para assegurar as condições adequadas de trabalho e de empreendedor capaz de promover mudanças e fazer adaptações necessárias. No exercício desses papéis, o gerente precisa ser dotado sobretudo de capacidade lógico-analítica.

Adicionalmente, o sucesso no desempenho desses papéis exige que o gerente seja também líder, agente de ligação e manipulador de distúrbios e para tanto, é importante que tenha uma boa dose de conhecimento de conteúdo humanístico. Precisa ainda de algum conhecimento especializado para que possa exercer o papel de disseminador no âmbito da organização e/ou de porta-voz, interlocutor do cliente externo.

A implantação/difusäo de novas tecnologias, sejam elas criadas pela organização ou compradas de terceiros, significa a introdução de um produ to intangível, percebido principal- 


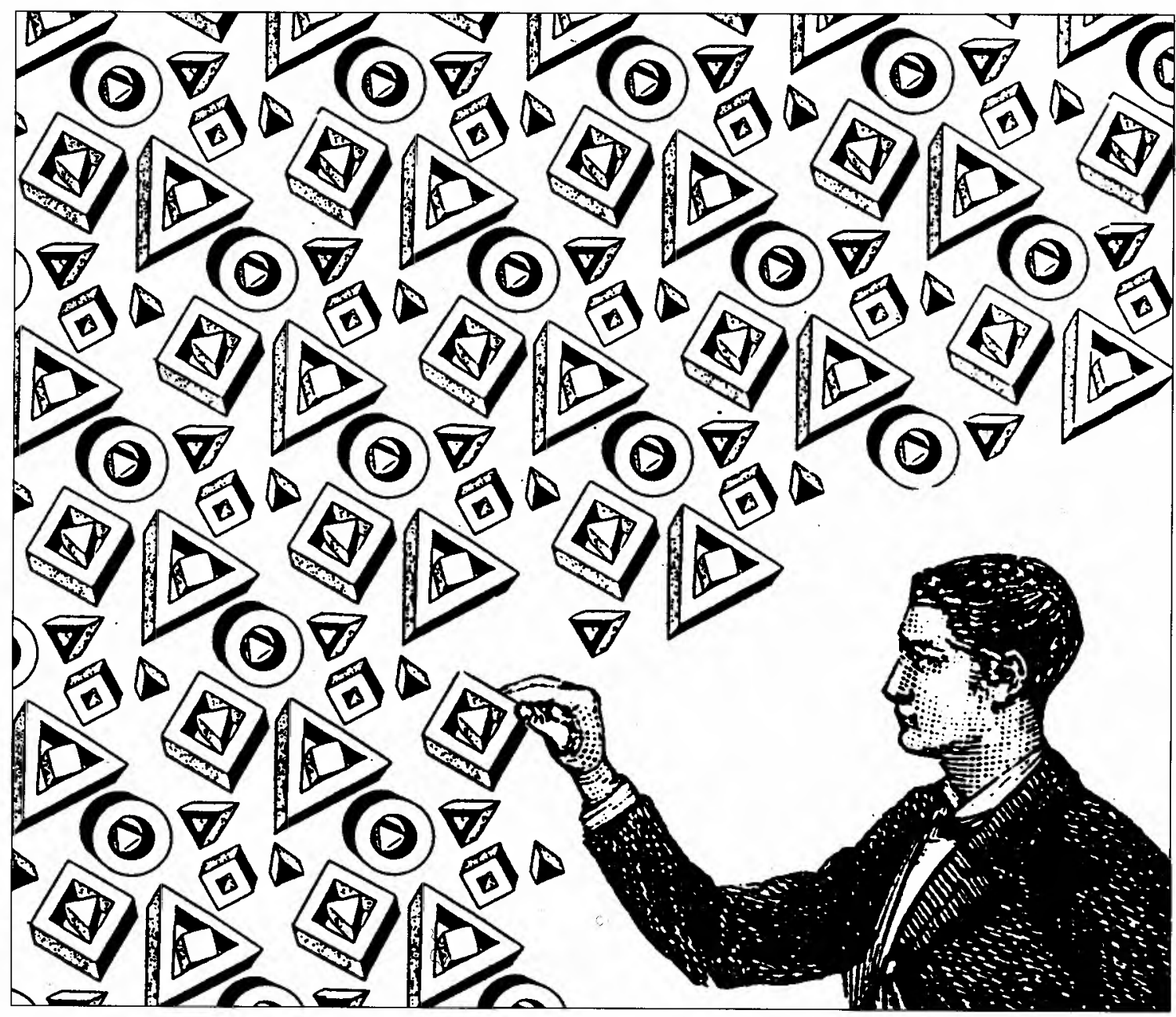

mente por suas implicações na organização do trabalho e estrutura organizacional. Os papéis de líder, agente de ligação e manipulador de distúrbio parecem ser os mais importantes, quando se trata de gerenciar mudanças que afetam o conteúdo do trabalho e, muitas vezes as relações de poder. O exercício desses papéis requer conhecimento humanístico, mas a implantação de novas tecnologias vai requerer também, capacidade lógico-analítica do gerente para desempenhar os papéis de empreendedor, negociador e alocador de recursos; e conhecimento especializado suficiente para que possa trabalhar como disseminador da informação.

O monitoramento tecnológico é o acompanhamento do desenvolvimento tecnológico e/ou da evolução do conhecimento, i.e., a procura de um recurso escasso que pode ou não estar materializado num produto. Obviamente, o papel de monitor assume primazia no exercício dessa atividade, juntamente com os papéis de disseminador e porta-voz. Para o monitoramento tecnológico, o conhecimento especializa- do é da maior importância, mas o gerente precisará também de conhecimento humanístico para exercer os papéis de agente de ligação e negociador, muitas vezes essenciais para ter acesso às fontes de informação relevantes.

Resumindo, estamos argumentando que existe um espectro variado de atividades relativas à tecnologia. Podemos listar as características da tecnologia mais relevantes para o exercício de cada uma dessas atividades e daí inferir e hierarquizar os papéis gerenciais mais importantes em cada uma. Propomos então que o desenvolvimento de habilidades gerenciais está associado à bagagem de conhecimento do indivíduo, que deve variar conforme o papel exigido do gerente em cada caso. Como resultado deste trabalho especulativo, sugerimos que as dimensões da gerência da tecnologia possam ser definidas de acordo com o conteúdo do conhecimento mais relevante para o exercício de cada atividade e que são no mínimo três: a dimensão especializada, a dimensão humana e a dimensão lógico-analítica. 